\title{
Perbedaan Kadar Hemoglobin, Asupan Zat Besi, dan Zinc pada Balita Stunting dan Non Stunting
}

\section{The Differences of Hemoglobin Level, Iron, and Zinc Intake in Stunting and non Stunting Toodler}

\author{
Nathania Helsa F. Losong ${ }^{* 1}$, Merryana Adriani ${ }^{1}$
}

\begin{abstract}
ABSTRAK
Latar belakang: Stunting merupakan masalah gizi kronis pada anak-anak yang menyebabkan terganggunya pertumbuhan linear anak dan diakibatkan oleh pola asuh dan asupan yang rendah.Rendahnya asupan zat gizi makro maupun mikro dapat mempengaruhi kejadian stunting pada balita. Asupan zat besi dan zinc dapat mempengaruhi kejadian stunting karena zat besi dan zinc mempengaruhi hormon pertumbuhan. Selain itu, asupan zat besi yang rendah dapat mempengaruhi kadar hemoglobin dalam tubuh.

Tujuan: Menganalisis perbedaan kadar hemoglobin dan asupan zat besi serta zinc dari makanan pada balita stunting dan non stunting.

Metode: Penelitian ini merupakan penelitian observasional analitik dengan desain cross sectional. Sampel terdiri dari 42 balita berusia 12-24 bulan di wilayah Kerja Puskesmas Tambak Wedi Kecamatan kenjeran Surabaya, balitastunting dannonstunting masing-masing sebesar 21 sampel.Pengumpulan data menggunakan pengukuran tinggi badan, food recall $2 \times 24$ jam, dan pengambilan sampel darah untuk pengukuran kadar hemoglobin menggunakan metode cyanmethemoglobin. Data dianalisis menggunakan chi square test dan fisher test.

Hasil: Hasil dari penelitian ini adalah terdapat perbedaan kadar hemoglobin $(p=0,009)$, asupan zat besi $(p=0,004)$, dan zinc $(p=0,000)$ pada anak stunting dan non stunting.

Kesimpulan: Balita stunting memiliki kadar hemoglobin dan asupan zat besi dan zinc yang lebih rendah daripada balita non stunting. Ibu balita sebaiknya meningkatkan variasi asupan sumber zat besi dan zinc agar dapat mencegah terjadinya stunting di masa yang akan datang.
\end{abstract}

Kata Kunci: stunting, kadar hemoglobin, asupan zat besi, asupan zinc 


\section{ABSTRACT}

Background: Stunting is a chronic nutritional problem in children cause growth retardation which caused by poor parenting and inadequate intake. Low intake of macro nutrient and micro nutrient can affect to stunting in toddler. Intake of iron and zinc affect the incidence of stunting because iron and zinc affect growth hormone. In addition, low iron intake can affect hemoglobin levels in the body Objectives: The purpose of this study was to analyze the differences of hemoglobin level, iron and zinc intake in stunting and non stunting toddler.

Methods: The research was an observational analytic with cross sectional design. The sample of this study were 42 toddler12-24 months in Tambak Wedi Public Health Center, Kenjeran Sub-district, Surabaya, 21 toddler each stunting and non stunting. The data were collected by measuring height, food recall $2 \times 24$ hours, and blood sampling for hemoglobin measurement with cyanmethemoglobin method. The data were analyzed using chi square test and fisher test.

Results: The result of this study showed there was difference of hemoglobin level $(p=0.009)$, iron intake $(p=0.004)$, and zinc intake $(p=0.000)$

Conclusion: Stunting toddler have a lower hemoglobin level, iron and zinc intake more than non stunting toddler. Mother of toddler should have to increase the variant food source iron and zinc to prevent stunting in the future.

Keywords: stunting, hemoglobin level, iron intake, and zinc intake

\footnotetext{
*Koresponden:

nathaniahelsa@ymail.com

${ }^{1}$ Departemen Gizi Kesehatan, Fakultas

Kesehatan Masyarakat-Universitas Airlangga
} 


\section{PENDAHULUAN}

Stunting merupakan status gizi anak berdasarkan panjang atau tinggi badan menurut umur berdasarkan standar WHOMGRS (Multicentre Growth Reference Study) dengan hasil z-score kurang dari - 2 standar deviasi merupakan kategori stunting ${ }^{1}$. Stunting merupakan gangguan pertumbuhan fisik yang ditandai dengan penurunan kecepatan pertumbuhan dan merupakan dampak dari ketidakseimbangan gizi ${ }^{2}$. Stunting masih merupakan satu masalah gizi di Indonesia yang belum terselesaikan. Prevalensi balita stunting di Indonesia masih fluktuatif sejak tahun 2007-2013. Prevalensi balita stunting di Indonesia pada tahun 2007 adalah 36,8\%, tahun 2010 sebesar 35,6\%, dan pada tahun 2013 sebesar $37,2 \%^{3}$.

Stunting akan menyebabkan dampak jangka panjang yaitu terganggunya perkembangan fisik, mental, intelektual, serta kognitif. Anak yang terkena stunting hingga usia 5 tahun akan sulit untuk diperbaiki sehingga akan berlanjut hingga dewasa dan dapat meningkatkan risiko keturunan dengan berat badan lahir yang rendah (BBLR) ${ }^{4}$. Menurut Oktarina and Sudiarti, ada banyak faktor yang meningkatkan risiko terkena stunting pada balita. Faktor tersebut antara lain ekonomi keluarga, jumlah anggota keluarga, fasilitas air bersih, pelayanan kesehatan, serta asupan zat gizi ${ }^{5}$. Pola asuh juga berperan dalam terjadinya stunting. Balita yang tidak mendapatkan pola asuh yang benar, akan menyebabkan balita tidak mendapatkan asupan zat gizi yang sesuai dengan kebutuhannya sehingga akan mempengaruhi pertumbuhan linear balita ${ }^{6}$.

Kejadian stunting tidak pernah lepas dari asupan zat gizi makro seperti energi, protein, serta lemak. Akan tetapi, asupan mineral makro seperti zat besi dan zinc juga perlu diperhatikan. Asupan zat besi yang rendah dapat menyebabkan terganggunya fungsi kognitifdan pertumbuhan balita, selain itu zat besi juga berperan dalam kekebalan tubuh agar balita tidak mudah terserang penyakit ${ }^{7}$. Selain asupan zat besi, asupan zinc juga perlu untuk diperhatikan. Asupan zinc yang kurang dapat menghambat efek metabolit hormon pertumbuhan sehingga menyebabkan sintesis dan sekresi IGF-1 (Insulin Like Growth Factor 1) menjadi berkurang. Penurunan sekresi tersebut menyebabkan stunting ${ }^{8}$. Hubungan stunting dan anemia ditunjukkan oleh penelitian Ayoya, et al (2013) yang menunjukkan bahwa terdapat hubungan antara kejadian stunting dengan kejadian anemia. Bahkan salah satu penelitian di Ghana menunjukkan bahwa balita stunting memiliki risiko 2 kali lebih besar terkena anemia daripada balita non stunting ${ }^{9}$

Prevalensi balita stunting di Surabaya masih cukup tinggi yaitu $21,5 \%$ pada tahun 2014. Salah satu daerah di Surabaya dengan prevalensi balita stunting yang cukup tinggi adalah Kelurahan Tambak Wedi yaitu sebesar 33\% pada tahun 2016. Angka tersebut tentunya cukup tinggi sehingga perlu adanya perhatian dan penanganan khusus baik dari instansi kesehatan maupun orang yang mengasuh balita agar tidak menimbulkan masalah gizi yang lebih besar di masa yang akan datang. Tujuan dari penelitian ini adalah untuk menganalisis perbedaan kadar hemoglobin, dan asupan zat besi, zinc pada balita stunting dan non stunting di Kelurahan Tambak Wedi Kecamatan Kenjeran Surabaya agar dapat melakukan tindakan pencegahan melalui asupan zat gizi balita.

\section{METODE}

Penelitian ini merupakan penelitian observasional analitik dengan desai cross sectional. Sampel dalam penelitian ini adalah balita 12-24 bulan di Kelurahan Tambak Wedi Kecamatan Kenjeran Surabaya dengan pengukuran z-score status gizi tinggi badan menurut umur yaitu $<-2$ SD atau stunting dan yang memiliki pengukuran $z$-score $\geq-2$ SD atau non stunting. Besar sampel dalam penelitian ini adalah 21 balita untuk masing-masing pada kedua kelompok dan diambil menggunakan proportional random sampling yang dilakukan pada seluruh sub populasi di Kelurahan Tambak Wedi Kecamatan Kenjeran yang merupakan wilayah kerja Puskesmas Tambak Wedi Surabaya.

Variabel yang diamati adalah kejadian stunting pada balita, dan variabel bebas dalam penelitian ini adalah kadar hemoglobin, serta 
asupan zat besi dan zinc. Karakteristik balita yang diteliti adalah usia balita dan jenis kelamin balita dengan kuisioner, sedangkan karakteristik keluarga dalam penelitian ini adalah pendidikan ibu dan pendapatan keluarga dengan kuisioner, kemudian dilakukan pengukuran tinggi badan, asupan makanan, serta pengambilan sampel darah. Usia balita digolongkan menjadi tiga kategori yaitu 12-16 bulan, 17-20 bulan, dan 21-24 bulan. Pendapataan keluarga dibagi menjadi 4 kuartil. Kuartil 1 dengan pendapatan $\leq \mathrm{Rp}$ 2.000.000, kuartil 2 dengan pendapatan $>\mathrm{Rp}$ 2.000.000 sampai dengan $\leq \mathrm{Rp} 2.275 .000$, kuartil 3 dengan pendapatan > Rp 2.275.000 sampai dengan $\leq$ Rp 3.000.000, dan kuartil 4 dengan pendapatan > Rp 3.000.000. Pengukuran tinggi badan menggunakan alat microtoise dan dimasukkan ke dalam software WHO Antro. Pengukuran kadar hemoglobin dilakukan di Laboratorium Fakultas Kesehatan Masyarakat Universitas Airlangga oleh analis medis yang profesional menggunakan cyanmethemoglobin $\quad\left(\right.$ Gandasoebrata,2006) ${ }^{10}$ dengan cut off point $<11 \mathrm{~g} / \mathrm{dL}$ kategori anemia dan $\geq 11 \mathrm{~g} / \mathrm{dL}$ kategori normal. Asupan makanan balita menggunakan kuisioner recall $2 \times 24$ hours. Hasil dari dua kali recall tersebut kemudian dirata-rata dan dibandingkan dengan cut off point< EAR untuk kategori inadekuat dan $\geq E A R$ untuk kategori adekuat.
Analisis univariat dilakukan untuk melihat distribusi variabel yang diteliti meliputi karakteristik balita dan keluarga, sedangkan analisis bivariat digunakan untuk melihat perbedaan variabel pada kelompok balita stunting dan non stunting dengan menggunakan uji chi-square dan fisher test dengan tingkat kepercayaan $95 \%(\alpha=0,05)$.

Penelitian ini telah mendapatkan persetujuan dari komisi etik dari Fakultas Kesehatan Masyarakat dengan nomor 324KEPK yang dikeluarkan tanggal 13 Juni 2017 dan Bakesbangpol Kota Surabaya dengan nomor 070/5923/436.8.5/2017.

\section{HASIL DAN PEMBAHASAN}

Karakteristik balita dan keluarga pada tabel 1 menunjukkan bahwa persebaran balita stunting merata pada setiap golongan usia yaitu 33,33\% sedangkan pada balita non stunting paling banyak berada pada golongan usia 12-16 bulan. Kejadian stunting pada usia 12-24 bulan dapat terjadi karena golongan usia tersebut merupakan masa peralihan dari bayi menjadi anak. Pergeseran pola makan menjadi makanan padat menjadi salah satu faktor tingginya angka stunting pada usia tersebut.

Tabel 1. Distribusi Karakteristik Balita dan Karakteristik Keluarga Balita Stunting dan Non Stunting dengan Usia 12-24 Bulan di Keluarahan Tambak Wedi Kenjeran, Surabaya Tahun 2017.

\begin{tabular}{|c|c|c|c|c|}
\hline \multirow{3}{*}{ Karakteristik } & \multicolumn{4}{|c|}{ status stunting } \\
\hline & \multicolumn{2}{|c|}{ Stunting } & \multicolumn{2}{|c|}{ Non Stunting } \\
\hline & $\mathbf{n}$ & $\%$ & $\mathbf{n}$ & $\%$ \\
\hline \multicolumn{5}{|l|}{ UsiaBalita (bulan) } \\
\hline $12-16$ & 7 & 33,33 & 11 & 52,38 \\
\hline $17-20$ & 7 & 33,33 & 5 & 23,81 \\
\hline $21-24$ & 7 & 33,34 & 5 & 23,81 \\
\hline Total & 21 & 100,00 & 21 & 100,00 \\
\hline \multicolumn{5}{|l|}{ JenisKelamin (Balita) } \\
\hline Laki-Laki & 8 & 38,09 & 6 & 28,57 \\
\hline Perempuan & 13 & 61,91 & 15 & 71,43 \\
\hline Total & 21 & 100,00 & 21 & 100,00 \\
\hline \multicolumn{5}{|l|}{ Pendapatan Keluarga } \\
\hline Kuartil 1 & 9 & 42,86 & 6 & 28,57 \\
\hline Kuartil 2 & 2 & 9,52 & 4 & 19,05 \\
\hline Kuartil 3 & 9 & 42,86 & 7 & 33,33 \\
\hline Kuartil 4 & 1 & 4,76 & 4 & 19,05 \\
\hline Total & 21 & 100,00 & 21 & 100,00 \\
\hline
\end{tabular}


Tabel 2. Perbedaan Asupan Zat Besi dan Zinc Pada Balita Stunting dan Non Stunting di Kelurahan Tambak Wedi Kecamatan Kenjeran, Surabaya Tahun 2017.

\begin{tabular}{|c|c|c|c|c|c|}
\hline \multirow{3}{*}{ Asupan Balita } & \multicolumn{4}{|c|}{ status stunting } & \multirow{3}{*}{ nilai $p$} \\
\hline & \multicolumn{2}{|c|}{ Stunting } & \multicolumn{2}{|c|}{ Non Stunting } & \\
\hline & $\mathbf{n}$ & $\%$ & $\mathbf{n}$ & $\%$ & \\
\hline \multicolumn{6}{|l|}{ Zat Besi } \\
\hline Adekuat & 1 & 4,76 & 9 & 42,86 & \multirow{3}{*}{0,004} \\
\hline Inadekuat & 20 & 95,24 & 12 & 57,14 & \\
\hline Total & 21 & 100,00 & 21 & 100,00 & \\
\hline \multicolumn{6}{|l|}{ Zinc } \\
\hline Adekuat & 5 & 23,81 & 18 & 85,71 & \multirow{3}{*}{0,000} \\
\hline Inadekuat & 16 & 76,19 & 3 & 14,29 & \\
\hline Total & 21 & 100,00 & 21 & 100,00 & \\
\hline
\end{tabular}

Selain itu, interaksi lingkungan luar juga dapat meningkatkan terjadinya penyakit infeksi dan dapat meningkatkan risiko terkena stunting ${ }^{9}$. Jenis kelamin pada balita stuntingmaupun non stuntinglebih banyak pada perempuan yaitu berturut-turun $61,9 \%$ dan $71,43 \%$. Hal tersebut bertentangan dengan penelitian Roscha, et al (2013) yang menyatakan bahwa balita stunting lebih banyak berjeniskelamin laki-laki daripada perempuan. Hal tersebut disebabkan karena balita laki-laki membutuhkan energi protein lebih besar daripada perempuan. Akan tetapi, hal ini sesuai dengan penelitian di Nigeria bahwa balita stunting lebih banyak berjeniskelamin perempuan $(50,3 \%)^{11}$. Pendapatan keluarga pada balita stunting sebagia besar berada pada kuartil 1 (pendapatan $\leq \mathrm{Rp} 2.000 .000$ ) dan kuartil 3 (pendapatan > Rp 2.275 .000 sampai dengan $\leq$ Rp 3.000.000) yaitu 42,86\%, sedangkan pada balita non stunting sebagian besar berada pada kuartil 3 sebesar 33,34\%. Hasil penelitian tersebut sesuai dengan penelitian yang dilakukan di pedesaan dan perkotaan bahwa pendapatan keluarga balita stunting paling banyak berada pada kategori yang rendah yaitu $93,3 \%^{12}$. Faktor sosial ekonomi merupakan penyebab tidak langsung terjadinya stunting. Status ekonomi yang rendah akan mempengaruhi kemampuan keluarga dalam pemenuhan gizi balita serta kemampuan untuk memperoleh pelayanan kesehatan yang layak ${ }^{13}$.

Tabel 2 menunjukkan asupan zat besi pada balita stunting sebagian besar berada pada kategori inadekuat yaitu $95,24 \%$ dan pada balita non stunting dengan kategori asupan adekuat adalah sebesar $42,86 \%$. Berdasarkan uji statistik diperoleh hasil terdapat perbedaan yang signifikan asupan zat besi pada kelompok stunting dan non stunting dengan nilai $p$ adalah 0,004 . Hal ini sesuai dengan penelitian yang dilakukan di 48 kabupaten di Indonesia bahwa asupan zat besi masih termasuk kategori rendah. Hal tersebut dikaitkan dengan masih kurangnya konsumsi makanan yang mengandung zat besi tinggi seperti daging, ikan, dan unggas. Kondisi sosial ekonomi yang rendah juga berhubungan langsung dengan rendahnya konsumsi zat gizi mikro. Rendahnya konsumsi zat besi juga dikaitkan dengan meningkatnya kebutuhan zat besi saat balita karena terkait pertumbuhan dan perkembangan balita ${ }^{14}$.Salah satu penelitian di Kenya juga menunjukkan bahwa balita yang diberikan suplemen besi dapat meningkatkan z-score panjang badan menurut umurnya ${ }^{15}$.

Tabel 2 juga menunjukkan bahwa asupan zinc pada balita stunting sebagian besar berada pada kategori inadekuat yaitu $76,19 \%$ dan pada balita non stunting dengan kategori asupan zinc yang adekuat yaitu sebesar $85,71 \%$. Berdasarkan uji statistik, terdapat perbedaan yang signifikan asupan zinc pada kelompok stunting dan non stunting dengan nilai $p$ adalah 0,000 . Hal tersebut sejalan dengan penelitian Damayanti et al (2016) yang menyatakan ada perbedaan asupan zinc pada balita stunting dan non stunting ${ }^{8}$. Pemberian suplementasi zinc pada anak dapat mempengaruhi pertumbuhan tinggi badan. 
Tabel 3. Perbedaan Kadar hemoglobin pada Balita Stunting dan Non Stunting di Kelurahan Tambak Wedi Kecamatan Kenjeran, Surabaya Tahun 2017.

\begin{tabular}{lccccc}
\hline \multirow{2}{*}{ Kadar Hemoglobin } & \multicolumn{4}{c}{ Status Stunting } & \multirow{2}{*}{ nilai $\boldsymbol{p}$} \\
\cline { 2 - 5 } & \multicolumn{3}{c}{ Stunting } & $\mathbf{n}$ & \multicolumn{2}{c}{ Non Stunting } & \\
\cline { 2 - 5 } & $\mathbf{n}$ & $\mathbf{\%}$ & $\mathbf{n}$ & $\mathbf{\%}$ & \\
\hline Rendah & 7 & 33,33 & 0 & 0,009 \\
Normal & 14 & 66,67 & 21 & 100,00 & \\
\hline Total & 21 & 100,00 & 21 & 100,00 & \\
\hline
\end{tabular}

Pengaruh tersebut disebabkan karena zinc merupakan salah satu zat gizi yang tergolong tipe 2. Zat gizi tipe 2 memiliki peran dalam fungsi dasar jaringan. Zinc juga merupakan salah satu zat gizi yang dibutuhkan dalam jumlah yang sedikit tetapi diperlukan secara terus-menerus karena tidak memiliki tempat penyimpanan ${ }^{16}$.

Asupan zat besi dan zinc diberikan secara bersamaan dengan dosis yang tepat agar mudah diserap oleh tubuh. Hal tersebut disebabkan karena zinc juga menggunakan transferin sebagai alat transpor yang juga merupakan alat transpor zat besi. Perbandingan asupan zat besi dan zinc sebaiknya tidak melebihi 2:1 agar tidak menghambat proses absorbsi ${ }^{16}$.

Tabel 3 menunjukkan bahwa balita stunting yang memiliki kadar hemoglobin yang rendah adalah sebesar 33,33\%, sedangkan balita non stunting yang memiliki kadar hemoglobin yang normal sebesar $100 \%$. Hasil uji statistika menunjukkan adanya perbedaan kadar hemoglobin pada balita stunting dan non stunting dengan nilai $p$ yaitu 0,009 . Hasil penelitian tersebut sejalan dengan penelitian Ayoya et al yang menyatakan adanya hubungan yang signifikan antara balita stunting dengan kejadian anemia ${ }^{9}$. Anemia dan stunting dapat muncul bersamaan karena setiap individu memiliki risiko untuk terkena masalah gizi kompleks. Balita stunting memiliki risiko untuk terkena anemia 2,3 kali lebih besar daripada balita dengan tinggi badan yang normal ${ }^{17,18}$. Rendahnya kadar hemoglobin tersebut dapat diakibatkan oleh beberapa faktor, antara lain rendahnya asupan zat gizi terutama zat besi, perdarahan, infeksi berulang, maupun rendahnya persediaan zat besi dalam tubuh ${ }^{19,20}$.

Penelitian ini mempunyai beberapa kekurangan. Kekurangan dari penelitian ini adalah penggunaan desain cross sectional menyebabkan pengumpulan data dilakukan pada satu waktu sehingga sulit untuk membedakan penyebab dan akibat. Selain itu, kekurangan dari penelitian ini adalah pengukuran pertumbuhan linear balita dengan melihat tinggi badan dan bukan panjang badan.

\section{KESIMPULAN}

Asupan zat besi dan zinc, serta kadar hemoglobin memiliki perbedaan yang signifikan pada balita stunting dan non stunting. Kadar hemoglobin ,asupan zat besi, dan zinc pada balita stunting lebih rendah daripada balita non stunting. Asupan makanan pada balita stunting perlu ditingkatkan terutama bahan makanan yang mengandung tinggi zat besi dan zinc agar dapat mencegah terjadinya stunting yang lebih lanjut. Perlu dilakukan penelitian lebih lanjut untuk mengetahui penyebab rendahnya kadar hemoglobin pada anak stunting.

\section{ACKNOWLEDGEMENT}

Terima kasih penulis berikan kepada: Badan Kesatuan Bangsa dan Politik Kota Surabaya, Dinas Kesehatan Kota Surabaya, dan Puskesmas Tambak Wedi Surabaya yang telah memberikan izin dalam pelaksanaan penelitian ini. Seluruh dosen dan staf Prodi Ilmu Gizi Universitas Airlangga terutama kepada dosen pembimbing atas bimbingan yang diberikan kepada penulis.

\section{REFERENSI}

1. Kementerian Kesehatan RI, 2016. Situasi Balita Pendek. Jakarta: 
www.depkes.go.id/resources/download/ pusdatin/.../situasi-balita-pendek2016.pdf [1 Agustus 2017]

2. Soegianto, S. D. W., andJawawi, 2007. Penilaian Status Gizi dan Baku Antropometri WHO-NCHS. Surabaya: CV. Duta Prima Airlangga.

3. Kementrian Kesehatan Republik Indonesia, 2017. Tahun 2015, Pemantauan Gizi Dilakukan di Seluruh Kabupaten/Kota di Indonesia. Jakarta: www.depkes.go.id. Tersedia di: www.depkes.go.id/resources/download/ pusdatin/.../situasi-balita-pendek2016.pdf [2 Mei 2017]

4. Kusudaryati, D. P. D., 2014. Kekurangan Asupan Besi dan Seng Sebagai Faktor Penyebab Stunting pada Anak. Jurnal Profesi, [e-journal]10(1).

5. Oktarina, Z., and Sudiarti, T., 2013. Faktor Risiko Stunting pada Balita (24-59 bulan) di Sumatera. Jurnal Gizi dan Pangan, [ejournal] 8(3): pp. 175-180.

6. Anugraheni, H. S., 2012. Faktor Risiko Kejadian Stunting pada Anak Usia 12-36 bulan di Kecamatan Pati, Kabupaten Pati [artikel penelitian]. Semarang: Program Studi IImu Gizi Fakultas Kedokteran Universitas Diponegoro.

7. Narendra, M.B. 2002. Tumbuh Kembang Anak dan Remaja. Jakarta: PT Sagung Seto

8. Damayanti, R. A., Muniroh, L., Farapti, 2016. Perbedaan Tingkat Kecukupan Zat Gizi dan Riwayat Pemberian Asi Eksklusif pada Balita Stunting dan Non Stunting. Media Gizi Indonesia [e-journal] 11(1) tahun 2016

9. Ayoya, M, Ag., Ngnie-Teta, I., Seraphin, M, N., Mamadoultaibou, A., Boldon, E., Saint-Fleur, J, E., Koo, L., Bernard, S., 2013. Prevalence and Risk Factors of Anemia among Children 6-59 Months Old in Haiti. Anemiavol 2013

10. Gandasoebrata, 2006. Penuntun Laboratorium Klinik. Jakarta: Dian Rakyat

11. Welasasih, B. D., and Wirjatmadi, B. R., 2012. Beberapa Faktor yang
Berhubungan dengan Status Gizi Balita Stunting. The Indonesian Journal of Public Health, [e-journal] 8(3): pp. 99-104. Tersedia $<$ http://journal.unair.ac.id/downloadfullpapers-

2.\%20Beberapa\%20Faktor\%20yang\%20B erhubungan\%20dengan.pdf> [diakses tanggal 17 April 2017]

12. Roscha, B.C., Putri, B.S.K., Putri, I.Y.S. (2013). Determinan Status Gizi Pendek Anak Balita dengan Riwayat Berat Badan Lahir Rendah (BBLR) di Indonesia (Analisis Data Riskesdas 2007-2010). Jurnal Ekologi Kesehatan, 12(3) 195-205. Diakses dari http://ejournal.litbang.depkes.go.id/inde x.php/jek/article/ download/3866/3716.

13. Aridiyah, F, O., Rohmawati, N., Ririanty, M., 2015. Faktor-faktor yang Mempengaruhi Kejadian Stunting pada Anak Balita di Wilayah Pendesaan dan Perkotaan. E-Jurnal Pustaka Kesehatan [e-journal] 3(1) Januari 2015

14. Fikrina, L. T., 2017. Hubungan Tingkat Sosial Ekonomi dengan Kejadian Stunting pada Balita 24-59 Bulan di Desa Karangrejek Wonosari Gunung Kidul. Skripsi. Yogyakarta. Program Studi Bidan Pendidik Jenjang Diploma IV Fakultas Ilmu Kesehatan Universitas 'Aisyiyah Yogyakarta.

15. Sumedi, A. and Sandjaja.2015. Asupan Zat Besi, Vitamin A, dan Zink Anak Indonesia Umur 6-23 Bulan (Low Iron, Vitamin A, And Zinc Intake Of 6-23Month-Old Indonesian Children). Penelitian Gizi dan Makanan [e-journal] Vol 38 (2):167-175

16. Lawless, S.W., Latham, M.C., Stephenson, L.S., Kinoti, S.N. and Pertet, M.A. 1994. Iron Suplementation Improves Appetite and Growth in Anemic, Kenyan Primary School Children. J.of.Nutr. 124:645-654.

17. Kusudaryati, D. P. D., 2014. Kekurangan Asupan Besi dan Seng Sebagai Faktor Penyebab Stunting pada Anak. Jurnal Profesi,

[e-journal]10(1). 